\title{
Lower tidal volume at initiation of mechanical ventilation may reduce progression to acute respiratory distress syndrome: a systematic review
}

\author{
Brian M Fuller ${ }^{*}$, Nicholas M Mohr ${ }^{2}$, Anne M Drewry ${ }^{3}$ and Christopher R Carpenter ${ }^{4}$
}

\begin{abstract}
Introduction: The most appropriate tidal volume in patients without acute respiratory distress syndrome (ARDS) is controversial and has not been rigorously examined. Our objective was to determine whether a mechanical ventilation strategy using lower tidal volume is associated with a decreased incidence of progression to ARDS when compared with a higher tidal volume strategy.

Methods: A systematic search of MEDLINE, EMBASE, CINAHL, the Cochrane Library, conference proceedings, and clinical trial registration was performed with a comprehensive strategy. Studies providing information on mechanically ventilated patients without ARDS at the time of initiation of mechanical ventilation, and in which tidal volume was independently studied as a predictor variable for outcome, were included. The primary outcome was progression to ARDS.
\end{abstract}

Results: The search yielded 1,704 studies, of which 13 were included in the final analysis. One randomized controlled trial was found; the remaining 12 studies were observational. The patient cohorts were significantly heterogeneous in composition and baseline risk for developing ARDS; therefore, a meta-analysis of the data was not performed. The majority of the studies $(n=8)$ showed a decrease in progression to ARDS with a lower tidal volume strategy. ARDS developed early in the course of illness (5 hours to 3.7 days). The development of ARDS was associated with increased mortality, lengths of stay, mechanical ventilation duration, and nonpulmonary organ failure.

Conclusions: In mechanically ventilated patients without ARDS at the time of endotracheal intubation, the majority of data favors lower tidal volume to reduce progression to ARDS. However, due to significant heterogeneity in the data, no definitive recommendations can be made. Further randomized controlled trials examining the role of lower tidal volumes in patients without ARDS, controlling for ARDS risk, are needed. 2013 Fuller et al.; licensee BioMed Central Ltd. This is an open access article distributed under the terms of the Creative Commons Attribution License (http://creativecommons.org/licenses/by/2.0), which permits unrestricted use, distribution, and reproduction in any medium, provided the original work is properly cited.

\section{Introduction}

Close to 200,000 cases of acute lung injury (ALI) or acute respiratory distress syndrome (ARDS) occur annually in the United States [1,2]. It remains a leading cause of death in critically ill patients, with a mortality rate of approximately $30 \%$, but as high as $60 \%$ in the elderly

\footnotetext{
* Correspondence: fullerb@wusm.wustl.edu

'Department of Anesthesiology, Division of Critical Care, Division of Emergency Medicine, Washington University in St. Louis School of Medicine, 660 South Euclid Avenue, St. Louis, MO, USA

Full list of author information is available at the end of the article
}

$[1,3,4]$. ARDS also represents a large societal burden, accounting for 3.6 million hospital days annually and significant long-term sequelae in survivors $[1,3]$. These include various neuropsychological impairments (e.g. depression, cognitive decline), persistent weakness and pulmonary dysfunction, and decreased quality of life $[3,5]$.Unfortunately, the number of ARDS trials demonstrating improved clinical outcomes are far outnumbered by those that have not [6-21]. In patients with ARDS, the current body of evidence supports a lower tidal volume strategy as best practice [6].

\section{Biomed Central}

(c) 2013 Fuller et al.; licensee BioMed Central Ltd. This is an open access article distributed under the terms of the Creative Commons Attribution License (http://creativecommons.org/licenses/by/2.0), which permits unrestricted use, distribution, and reproduction in any medium, provided the original work is properly cited. 
In contrast, the optimal tidal volume in patients without ARDS is uncertain [22,23]. Historically, it was thought that high tidal volume not only was safe, but also was preferred to avoid the hypoxia, atelectasis, and acidosis associated with mechanical ventilation with lower tidal volumes [24-26]. This led to the common use of tidal volumes in the 12 - to $15-\mathrm{ml} / \mathrm{kg}$ range [27]. However, experimental data suggest that tidal volume is a major contributor to the development of lung injury [28]. Clinical data in intensive care unit (ICU) patients also suggests that larger tidal volume may contribute to the development of ARDS [29-31], suggesting that this syndrome may in part be preventable. However, this evidence has been inconclusive, because of observational trial design, small sample sizes, and lack of reproducibility in different patient populations $[32,33]$. In patients without lung injury at the time of endotracheal intubation, progression to ARDS can occur over the course of hours and may increase mortality by $>30 \%[30,34,35]$. This has led to increased interest in ARDS prevention and the examination of a lower tidal volume strategy to prevent its development in patients without lung injury.

We therefore aimed to systematically review the evidence regarding the role of tidal volume as a contributor to ARDS progression in patients without ARDS. The objectives of this study were to perform a systematic review of the literature comprising a comprehensive search strategy and standardized analysis techniques to determine whether lower tidal volumes, compared with higher tidal volumes, are associated with a decreased incidence of ARDS in mechanically ventilated patients. We hypothesized that lower tidal volume ventilation is associated with a decrease in progression to ARDS in mechanically ventilated patients, but the existing literature lacks the methodologic quality to provide definitive recommendations for the best tidal volume in patients without ARDS.

\section{Materials and methods}

This systematic review was designed, conducted, and reported in accordance with the Preferred Reporting Items for Systematic Reviews and Meta-Analysis (PRISMA) and Meta-analysis of Observational Studies in Epidemiology (MOOSE) guidelines [36,37]. It did not require ethical approval from Washington University Human Research Protection Office. It is recognized that ALI and ARDS have undergone recent definitional change [38]. Although the definitional criteria in place during the systematic search for clinical trials, as well as the conduct of each study, was the American-European Consensus Conference (AECC) criteria, for consistency in reporting according to the new Berlin definition, we use the term ARDS to refer to both ARDS and ALI (as reported in previous literature) $[2,38]$.

\section{Search for and identification of studies}

We followed a written protocol (see Additional file 1) that was finalized before beginning the search. We initiated our timeline from 1967 (first description of ARDS) through 2011 and searched MEDLINE, EMBASE, CINAHL, and the Cochrane Library, by using a combination of standardized search terms and keywords covering the basic concepts of acute lung injury, acute respiratory distress syndrome, mechanical ventilation, ventilator-induced lung injury, prevention, outcomes, and clinical trial. A trained information professional experienced in systematic reviews assisted in designing the search strategy and in conducting the search. Two authors (BMF, NMM) also manually screened the reference lists of the articles selected for inclusion to identify additional studies. To identify potential unpublished data from clinical trials that have completed enrollment, BMF and NMM also (a) manually searched abstracts from the Society of Critical Care Medicine, European Society of Intensive Care Medicine, American Society of Anesthesiology, American Thoracic Society, CHEST, and the Society of Academic Emergency Medicine from 2008 to 2011; and (b) searched online for details of clinical trials registration (http://ClinicalTrials. gov). BMF also contacted principal investigators of published and unpublished studies for clarification of potential data for inclusion, as needed.

\section{Inclusion criteria}

Studies were eligible for review regardless of language or publication type. We included randomized controlled trials, prospective and retrospective cohort analyses, crosssectional studies, and before-and-after trials of adults (older than 17 years) undergoing invasive positive-pressure ventilation without ARDS at the time of initiation of mechanical ventilation, and in which tidal volume was independently studied (either retrospectively or prospectively) as a predictor variable for outcome. We excluded studies involving patients with established ARDS by consensus criteria [2], studies of nonintubated patients (e.g. noninvasive positive-pressure ventilation), studies of one-lung ventilation, studies in which tidal volume was not the only ventilator variable studied or manipulated (e.g. tidal volume and positive end-expiratory pressure), and studies in which the development of ARDS was not a primary or secondary outcome measure. We also excluded articles that were reviews, correspondence, editorials, and nonhuman studies. We screened the reference list of all review articles to identify additional studies for inclusion. Corresponding authors were contacted, where appropriate, for clarification of data or study type.

\section{Study selection and data abstraction}

Two reviewers (BMF and NMM) independently screened the titles and abstracts of identified studies for potential 
eligibility. After this relevance screen, full text articles were assessed for eligibility, and the two reviewers compared their exclusion logs to determine whether there was disagreement. All studies deemed potentially relevant after the screen were obtained, and the full manuscripts were reviewed for further exclusion. In cases of disagreement, a third reviewer (AD) assessed the study, and a consensus was reached between the three reviewers. Any disagreements in this collection were resolved with a consensus among the reviewers.

\section{Assessment of study quality}

We assessed the quality of clinical trials selected for inclusion by using the Cochrane Collaboration's tool for assessing the risk of bias in clinical trials, evaluating four domains: random sequence generation, concealment of allocation, blinding, and selective outcome reporting [39]. High quality was defined as a grade of $\mathrm{A}$ in at least three of the four methodology domains. For studies of observational design, each was assessed for its reporting of adherence to the Strengthening the Reporting of Observational Studies in Epidemiology (STROBE) Statement [40].

\section{Assessment of publication bias}

Because detecting publication bias is difficult, we sought to minimize bias through a medical librarian assisted comprehensive search strategy and the use of study registries. We planned to use a graphic display (funnel plot) of the size of the treatment effect against the precision of the trial to evaluate for potential publication bias [41].

\section{Data analysis}

Our original intent, after conducting the systematic review, was to conduct a meta-analysis of the data by using Review Manager (RevMan, Version 5.1, Copenhagen: The Nordic Cochrane Centre, The Cochrane Collaboration, 2011). However, because of qualitative heterogeneity between the studies with respect to the patient populations studied and the baseline risk for ARDS development, this was not possible. RevMan was used to generate the funnel plot.

\section{Results}

\section{Search and selection}

The comprehensive search yielded a total of 1,704 potentially relevant publications. Details regarding the search, study selection, and reason for exclusion are shown in Figure 1.

\section{Inclusion}

After the relevance search, a complete manuscript review was performed on the remaining 52 articles. Thirteen studies were included in the final analysis
[29-31,34,35,42-49]. The characteristics of the included studies are shown in Table 1.

\section{Study characteristics and outcomes reporting}

The 13 studies were published over a 7-year period (2004 through 2011). One study was a randomized controlled trial (RCT), and 12 were of observational trial design. On the methodologic quality assessment, the RCT was rated as high quality by Cochrane Collaboration's tool for assessing the risk of bias in clinical trials. In this trial, Grade A was given for random-sequence generation (sequence adequately generated), concealment of allocation (performed concealment allocation), and selective outcome reporting (free of suggestion of selective outcome reporting). For clinical trials in which blinding is not feasible at the point of intervention (potential methodologic issue for mechanical ventilation trials), high quality can still be assigned if the investigator collecting the primary outcome is blinded to the treatment allocation. This was unclear in the included RCT; therefore, a grade $\mathrm{C}$ was given for blinding (unknown whether investigators collecting the primary outcome were blinded to allocation). None of the 12 observational trials reported any adherence to the STROBE guidelines [40]. Two of the trials were multicenter studies (one retrospective registry and one prospective observational trial), and 11 were performed at a single center. Ten trials involved interventions and patients in medical, surgical, neurologic, trauma, or cardiac ICUs. Three trials were from the operating room. No studies examined mechanical ventilation in the Emergency Department (ED). Two of the studies were presented in abstract form only.

Significant heterogeneity was found with respect to the patient population studied and the diagnoses leading to respiratory failure (Table 1). Examples include cardiac arrest, neurologic disorders such as subarachnoid hemorrhage and traumatic brain injury, postoperative patients, sepsis, and elective surgical patients. Visual inspection of the funnel plot (Figure 2) indicated potential publication bias, because observed asymmetry suggested unpublished research that favored not using low tidal volumes [41]. Although ARDS was defined according to the AECC criteria in each of the studies, differences existed in given criteria between studies [2]. For example, two studies required the criteria to be fulfilled for 2 consecutive days [29,45]; one study required criteria for 24 hours [47]; one study required criteria for three consecutive arterial blood gases [31]; and one study allowed the criterion of left atrial hypertension to be determined at the discretion of the attending physician, "with the modality of their choice," when a pulmonary artery catheter was not in use, yet provided no further information on the diagnostic modalities used [49]. Therefore, because of the very 


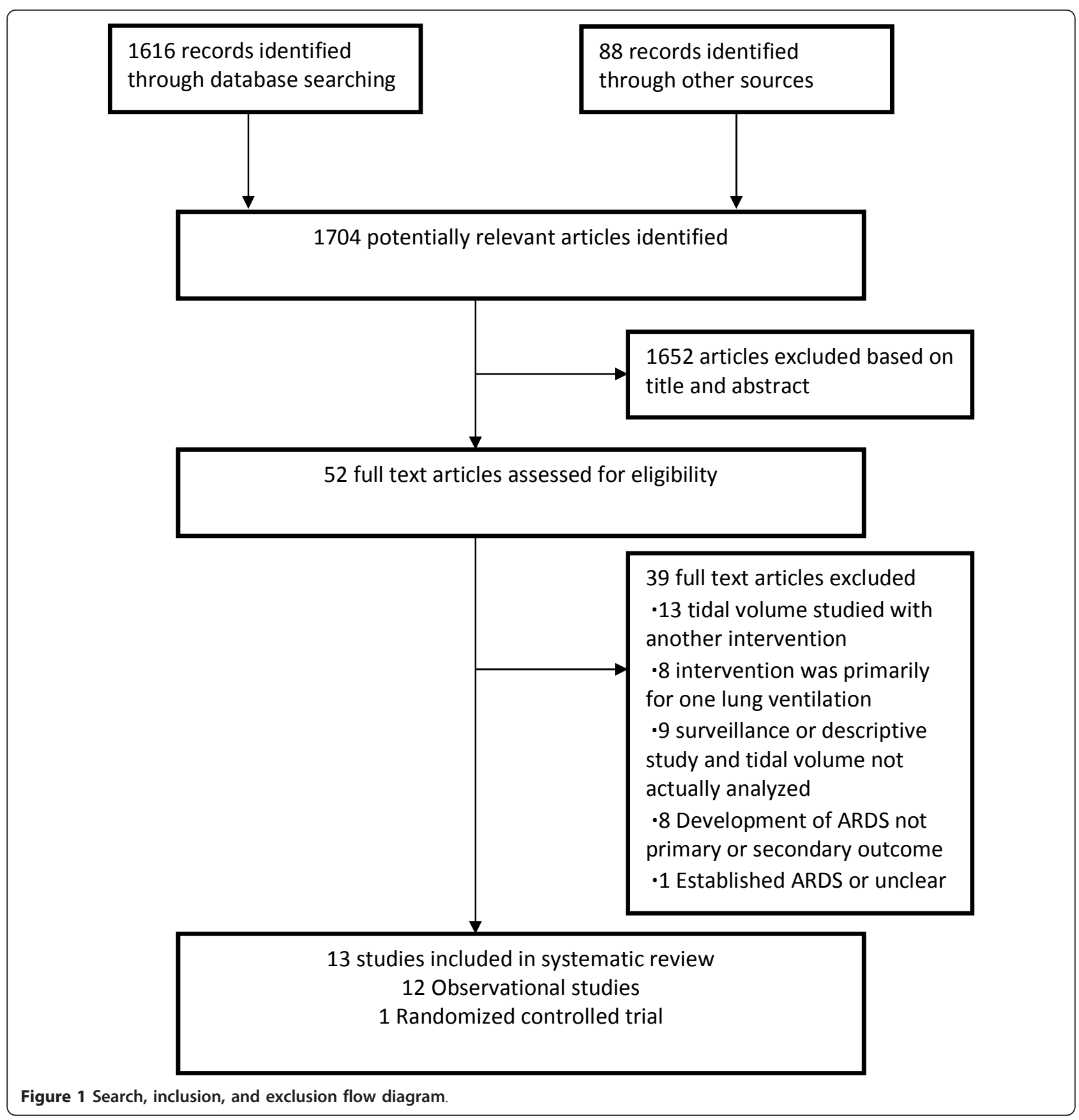

likely differences in baseline ARDS risk in the various studies' populations, as well as the uncertainty of diagnostic accuracy for ARDS, given the variable criteria used to define it, a meta-analysis was not performed as had been planned a priori.

\section{Clinical outcomes}

The results of the studies are shown in Table 2 . In the only RCT, a tidal volume of $6 \mathrm{ml} / \mathrm{kg}$ predicted body weight (PBW) was associated with an absolute risk reduction of
$10.9 \%$ for the development of ARDS (number needed to treat of 9.2) when compared with $10 \mathrm{ml} / \mathrm{kg}$ PBW. The observational studies included three operating room studies $(n=58,419)$, one of which demonstrated an association between tidal volume and the development of ARDS. However, in this largest trial included $(n=53,910)$ in the review, the tidal volume difference between the two groups was not clinically significant $(0.1 \mathrm{ml} / \mathrm{kg} \mathrm{PBW})$. Nine of the observational studies were from the ICU $(n=$ 8,165 ), six of which showed tidal volume (mean tidal 
Table 1 Study characteristics

Randomized controlled trial

\begin{tabular}{|c|c|c|c|c|c|c|c|c|}
\hline Author, year & $n$ & Intervention & Location & $\begin{array}{l}\text { Primary patient } \\
\text { population }\end{array}$ & $\begin{array}{l}\text { High- } \\
\text { quality } \\
\text { RCT? }^{\mathrm{a}}\end{array}$ & $\begin{array}{l}\text { Primary } \\
\text { outcome }\end{array}$ & Secondary outcome & Comments $^{\mathrm{b}}$ \\
\hline $\begin{array}{l}\text { Determann, } \\
2010\end{array}$ & 150 & $\begin{array}{l}\mathrm{VT} 6 \mathrm{ml} / \mathrm{kg} \\
\text { PBW vs. } 10 \\
\mathrm{ml} / \mathrm{kg} \text { PBW }\end{array}$ & Medical/surgical ICU & $\begin{array}{l}\text { Cardiac arrest, neurologic } \\
\text { disease }\end{array}$ & YES & $\begin{array}{l}\text { Cytokine levels in } \\
\text { BAL and plasma }\end{array}$ & Development of ARDS & $\begin{array}{l}\text { Could be randomized up to } 36 \text { hours after } \\
\text { mechanical ventilation }\end{array}$ \\
\hline \multicolumn{9}{|c|}{ Observational studies } \\
\hline \multicolumn{9}{|l|}{ Cohort studies } \\
\hline Author, year & $n$ & Study design & Location & Primary patient diagnoses & $\begin{array}{l}\text { High } \\
\text { quality }^{c}\end{array}$ & $\begin{array}{l}\text { Primary } \\
\text { outcome }\end{array}$ & Secondary outcomes & Comments \\
\hline Gajic, 2004 & 332 & Retrospective & Medical/surgical ICUs & Shock, sepsis & NO & $\begin{array}{l}\text { Development of } \\
\text { ARDS }\end{array}$ & $\begin{array}{l}\text { Hospital mortality, } \\
\text { ventilator-free days }\end{array}$ & Excluded patients ventilated $<48$ hours \\
\hline Gajic, 2005 & 3,261 & Retrospective & $\begin{array}{l}\text { Multicenter registry of } \\
\text { medical/surgical ICUs }\end{array}$ & $\begin{array}{l}\text { Postoperative, coma, } \\
\text { pneumonia }\end{array}$ & $\mathrm{NO}$ & $\begin{array}{l}\text { Development of } \\
\text { ARDS }\end{array}$ & None mentioned & Excluded patients ventilated $<48$ hours \\
\hline Kahn, 2006 & 620 & Retrospective & Neuro ICU & $\begin{array}{l}\text { Aneurysmal subarachnoid } \\
\text { hemorrhage }\end{array}$ & NO & $\begin{array}{l}\text { Development of } \\
\text { ARDS }\end{array}$ & $\begin{array}{l}\text { Incidence of lung- } \\
\text { protective ventilation }\end{array}$ & Tidal volume obtained from author contact. \\
\hline Mascia, 2007 & 82 & Prospective & Four European ICUs & $\begin{array}{l}\text { Severe traumatic brain } \\
\text { injury }\end{array}$ & NO & $\begin{array}{l}\text { Development of } \\
\text { ARDS }\end{array}$ & $\begin{array}{l}\text { ICU LOS, VF days, ICU } \\
\text { mortality }\end{array}$ & $\begin{array}{l}\text { Excluded patients with ARDS }<24 \text { hours from } \\
\text { admission }\end{array}$ \\
\hline Yilmaz, 2007 & 375 & $\begin{array}{l}\text { Prospective, } \\
\text { before-after }\end{array}$ & Medical/surgical ICU & Sepsis, pneumonia & $\mathrm{NO}$ & $\begin{array}{l}\text { Development of } \\
\text { ARDS }\end{array}$ & $\begin{array}{l}\text { Hospital mortality, } \\
\text { duration of ventilation, } \\
\text { ICU LOS, VF days }\end{array}$ & Excluded patients ventilated $<48$ hours \\
\hline Plurad, 2007 & 2,346 & Retrospective & Surgical ICU & Trauma & $\mathrm{NO}$ & $\begin{array}{l}\text { Development of } \\
\text { late ARDS }\end{array}$ & Not mentioned & $\begin{array}{l}\text { Defined late ARDS as }>48 \text { hours after } \\
\text { admission }\end{array}$ \\
\hline Iscimen, 2008 & 160 & Prospective & Medical ICU & Septic shock & NO & $\begin{array}{l}\text { Development of } \\
\text { ARDS }\end{array}$ & $\begin{array}{l}\text { Hospital mortality, } \\
\text { hospital length of stay }\end{array}$ & \\
\hline Jia, 2008 & 789 & Retrospective & $\begin{array}{l}\text { Medical/surgical/ } \\
\text { cardiac ICUs }\end{array}$ & Unclear & NO & $\begin{array}{l}\text { Development of } \\
\text { ARDS }\end{array}$ & Not mentioned & $\begin{array}{l}\text { Excluded patients ventilated <48 hours. } 341 \\
\text { patients had data missing on VT/PBW }\end{array}$ \\
\hline Pasero, 2008 & 200 & Prospective & Cardiac ICU & $\begin{array}{l}\text { Patient status after } \\
\text { cardiopulmonary bypass }\end{array}$ & NO & $\begin{array}{l}\text { Development of } \\
\text { ARDS }\end{array}$ & Not mentioned & Abstract only \\
\hline Hughes, 2010 & 89 & Retrospective & OR & $\begin{array}{l}\text { Abdominal, orthopedic, } \\
\text { vascular surgery within } 24 \\
\text { hours of ICU admit }\end{array}$ & NO & $\begin{array}{l}\text { Development of } \\
\text { ARDS }\end{array}$ & Not mentioned & $\begin{array}{l}\text { Assessed outcomes for } 7 \text { days. } \\
\text { Excluded many risks for ARDS development }\end{array}$ \\
\hline Blum, 2011 & 53910 & Retrospective & $\begin{array}{l}\text { OR: all } \\
\text { noncardiothoracic and } \\
\text { nontransplant } \\
\text { procedures }\end{array}$ & ASA I, II & NO & $\begin{array}{l}\text { Development of } \\
\text { ARDS }\end{array}$ & Not mentioned & Abstract only \\
\hline \multicolumn{9}{|c|}{ Case-control study } \\
\hline Author, year & $n$ & Study design & Location & Primary patient diagnoses & $\begin{array}{l}\text { High } \\
\text { quality }\end{array}$ & $\begin{array}{l}\text { Primary } \\
\text { outcome }\end{array}$ & Secondary outcomes & Comments \\
\hline $\begin{array}{l}\text { Fernandez- } \\
\text { Perez, } 2009\end{array}$ & 4,420 & $\begin{array}{l}\text { Prospective, } \\
\text { nested }\end{array}$ & $\begin{array}{l}\text { OR with general } \\
\text { anesthesia for } \geq 3 \\
\text { hours }\end{array}$ & Elective operations & $\mathrm{NO}$ & $\begin{array}{l}\text { Postoperative } \\
\text { respiratory failure } \\
\text { due to ARDS }\end{array}$ & $\begin{array}{l}\text { Length of stay, } 60 \text {-day } \\
\text { survival, 1-year survival }\end{array}$ & $\begin{array}{l}\text { Excluded patients with "prevalent" risk factors } \\
\text { for ARDS. } 1^{\text {st }} \text { hour ventilator variables were } \\
\text { primary predictor variable }\end{array}$ \\
\hline
\end{tabular}

${ }^{a}$ As assessed by Cochrane Collaboration's tool for assessing risk of bias in clinical trials. Was assigned a grade of " $\mathrm{A}$ " (high quality) in the following methodology domains: random-sequence generation, concealment of allocation, and selective outcome reporting; assigned a grade of " $\mathrm{C}$ " (unknown) in the following methodology domain: blinding. To explain, for trials in which blinding is not feasible at the point of intervention (such as a tidal volume trial), a grade of " $\mathrm{A}$ " would be assigned if the investigator collecting the primary outcome were blinded to the treatment allocation. " $\mathrm{F}$ For the RCT, there was no reported assessment of adherence to the ventilator/intervention protocol. ' As assessed by STROBE guidelines. ARDS, acute respiratory distress syndrome; ASA, American Society of Anesthesiologists; BAL, bronchoalveolar lavage; ICU, intensive care unit; LOS, length of stay; PBW, predicted body weight; VF, ventilator free; VT, tidal volume. 


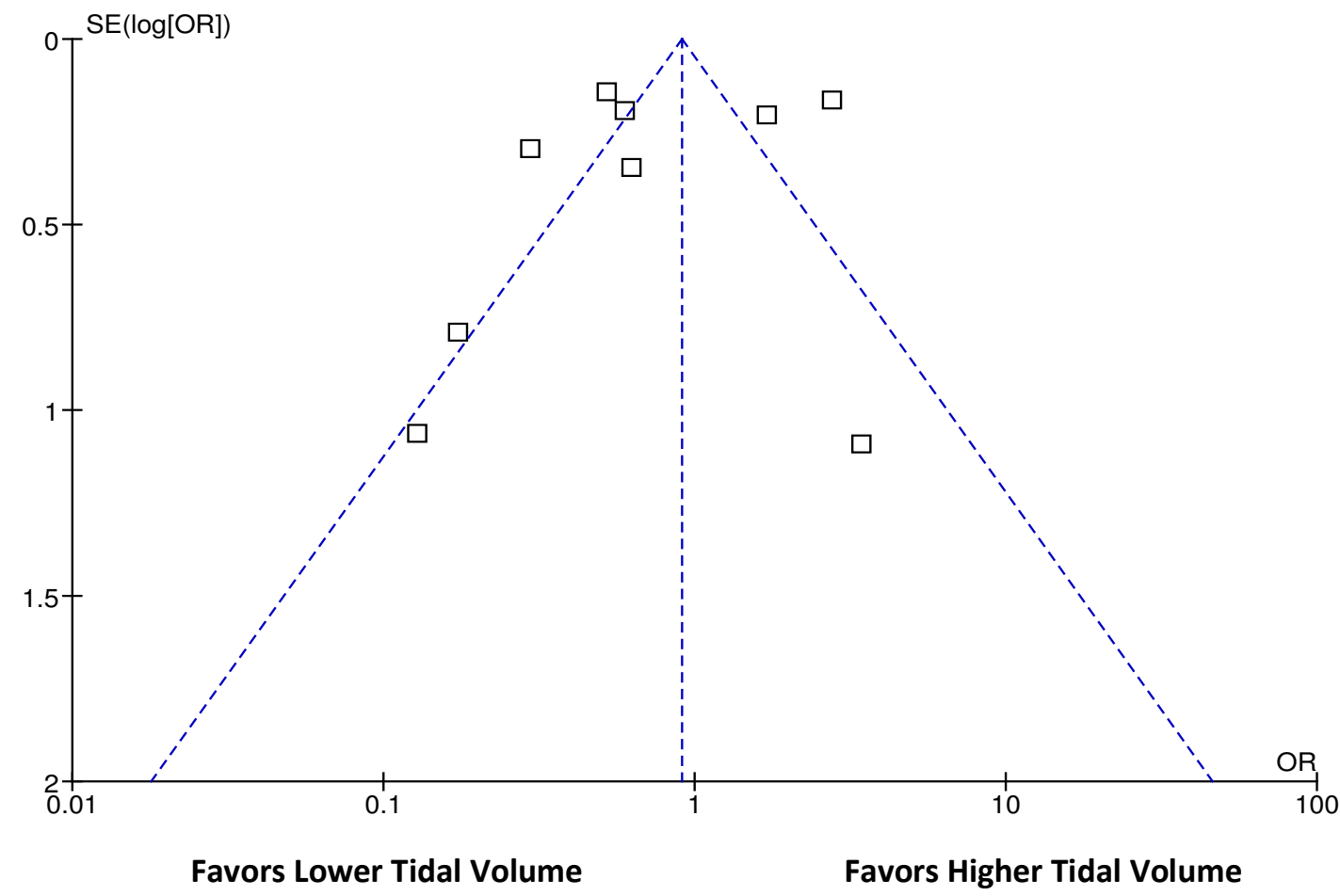

Figure 2 Funnel plot for assessment of publication bias.

volume or indexed to $\mathrm{PBW}$ ) to be an independent predictor of the development of ARDS. Five studies showed a dose-response relation to tidal volume, with the proportion of ARDS increasing with higher tidal volumes. No study reported adverse clinical effects in association with a lower tidal volume.

The time of ARDS onset was reported in seven studies, and occurred between days 2 and 4 ( 5 hours to 3.7 days). The incidence of ARDS was very low in the two operating room studies involving primarily elective procedures: $0.2 \%$ and $1.9 \%$. This is in contrast to a much higher incidence in ICU patients, ranging from $6.2 \%$ to $44 \%$.

In the studies comparing secondary outcomes between ARDS and non-ARDS groups, the development of ARDS increased mortality and morbidity. ARDS was associated with an absolute increase in mortality of up to $36 \%$, increased ICU and hospital lengths of stay, fewer ventilator-free days, and increased organ failure (Table 3).

\section{Discussion}

In patients who do not have ARDS at the time of endotracheal intubation, the preponderance of evidence implies an association between lower tidal volume and subsequent progression to ARDS. However, this systematic review could yield no definitive recommendations regarding the most appropriate tidal volume strategy in patients without ARDS. Several important caveats exist. An overall lack of data appears in the existing body of literature, as well as a lack of methodologic quality in the data that do exist. Of the 13 trials included in this review, only one was a high quality RCT, whereas the remainder were of observational trial design. None of the observational trials referenced the STROBE guidelines, which are endorsed by 110 journals worldwide [50]. Publication guidelines like STROBE were designed to standardize the reporting of medical research to enhance transparency and minimize variability [51]. An increasing body of evidence indicates that the guidelines do improve the overall quality of research reporting [52].

There was also substantial heterogeneity appeared in the patient populations examined, each carrying perhaps vastly different risk for ARDS progression. For example, relatively healthy patients with a finite exposure to tidal volume risk (operating room cases) are inherently different in risk for progression compared with critically ill ICU patients [53]. Furthermore, even among the studies restricted to patients with longer exposure to tidal volume (ICU patients), the diagnoses leading to mechanical ventilation (Table 1) also carry very different risk for ARDS (e.g. septic shock versus postoperative). Funnel-plot inspection for the assessment of publication bias revealed asymmetry suggestive of publication bias. However, asymmetric funnel plots are not sufficient 
Table 2 Study results

\begin{tabular}{llllllll}
\hline Randomized controlled trial & & & & \\
\hline Author, year & $\begin{array}{l}\text { Time of } \\
\text { ARDS } \\
\text { onset }\end{array}$ & $\begin{array}{l}\text { Incidence of } \\
\text { ARDS }\end{array}$ & $\begin{array}{l}\text { Experimental } \\
\text { ARDS rate }\end{array}$ & $\begin{array}{l}\text { Control ARDS } \\
\text { rate }\end{array}$ & OR & Comments \\
\hline Determann, 2010 & 1.9 days & $8 \%(n=12)$ & $2.6 \%(n=2)$ & $13.5 \%(n=10)$ & $5.1(1.2-22.6)$ & 0.01 & $\begin{array}{l}\text { Trial stopped early for safety, due } \\
\text { to ARDS in control. }\end{array}$ \\
\hline Observational studies & & & &
\end{tabular}

\begin{tabular}{|c|c|c|c|c|c|c|c|}
\hline \multicolumn{8}{|c|}{ Observational studies } \\
\hline \multicolumn{8}{|l|}{ Cohort studies } \\
\hline Author, year & $\begin{array}{l}\text { Time of } \\
\text { ARDS } \\
\text { onset }\end{array}$ & $\begin{array}{l}\text { Incidence of } \\
\text { ARDS }\end{array}$ & $\begin{array}{l}\text { VT ARDS } \\
\text { Group }\end{array}$ & $\begin{array}{l}\text { VT No-ARDS } \\
\text { Group }\end{array}$ & $\mathrm{OR}^{\mathrm{b}}$ & $p$ & Comments \\
\hline Gajic, 2004 & 2.5 days & $24 \%(n=80)$ & Unknown & Unknown & $1.29(1.12-1.51)$ & $<0.001$ & $\begin{array}{l}\text { Proportion of ARDS increased as } \\
V T \text { increased. }\end{array}$ \\
\hline Gajic, 2005 & Unknown & $6.2 \%(n=205)$ & $670 \mathrm{ml} \pm 220^{c}$ & $620 \mathrm{ml} \pm 110^{\mathrm{c}}$ & $1.26(1.12-1.40)$ & $<0.001$ & $\begin{array}{l}\text { Proportion of ARDS increased as } \\
\text { VT increased. }\end{array}$ \\
\hline Kahn, 2006 & 3 days & $27 \%(n=170)$ & $\begin{array}{l}9.1 \mathrm{ml} / \mathrm{kg} \\
\mathrm{PBW} \pm 1.8\end{array}$ & $\begin{array}{l}9.4 \mathrm{ml} / \mathrm{kg} \\
\mathrm{PBW} \pm 1.5\end{array}$ & NS & 0.06 & $\begin{array}{l}\text { ARDS development associated } \\
\text { with transfusion, SAH severity, and } \\
\text { PRBC transfusion. }\end{array}$ \\
\hline Mascia, 2007 & 2.8 days & $22 \%(n=18)$ & $\begin{array}{l}10.4 \mathrm{ml} / \mathrm{kg} \\
\mathrm{PBW} \pm 1.1^{\mathrm{b}}\end{array}$ & $\begin{array}{l}9.5 \mathrm{ml} / \mathrm{kg} \\
\mathrm{PBW} \pm 1.0^{\mathrm{c}}\end{array}$ & $5.54(1.54-9.24)$ & 0.008 & $\begin{array}{l}\text { Proportion of ARDS increased as } \\
\text { VT increased. }\end{array}$ \\
\hline Yilmaz, 2007\| & Unknown & $\begin{array}{l}28 \%(n=60) \\
\text { before } \\
\text { protocol; } 10 \% \\
(n=17) \text { after } \\
\text { protocol }\end{array}$ & Unknown & Unknown & $1.31(1.16-1.50)$ & $<0.001$ & $\begin{array}{l}\text { Proportion of ARDS increased as } \\
V T \text { increased. }\end{array}$ \\
\hline Plurad, 2007 & Unknown & $8.2 \%(n=192)$ & $\begin{array}{l}8.6 \mathrm{ml} / \mathrm{kg} \\
\mathrm{PBW} \pm 1.7\end{array}$ & $\begin{array}{l}8.8 \mathrm{ml} / \mathrm{kg} \\
\mathrm{PBW} \pm 2.3\end{array}$ & NS & 0.383 & $\begin{array}{l}\text { ARDS associated with fluid } \\
\text { balance and PRBC transfusion }\end{array}$ \\
\hline Iscimen, 2008 & 5 hours & $44 \%(n=71)$ & $\begin{array}{l}6.9 \mathrm{ml} / \mathrm{kg} \text { PBW } \\
(6.1-7.8)\end{array}$ & $\begin{array}{l}7.0 \mathrm{ml} / \mathrm{kg} \text { PBW } \\
(6.5-7.9)\end{array}$ & NS & 0.362 & $\begin{array}{l}\text { Delayed antibiotics and } \\
\text { resuscitation associated with ARDS }\end{array}$ \\
\hline Jia, 2008 & 3.3 days & $19 \%(n=152)$ & $\begin{array}{l}650.5 \mathrm{ml} \pm \\
119.7^{c}\end{array}$ & $616.9 \mathrm{ml} \pm 112.8^{c}$ & $1.33(1.09-1.62)$ & 0.006 & $\begin{array}{l}\text { Proportion of ARDS increased as } \\
V T \text { increased. Transfusion, fluid } \\
\text { balance, airway pressures also } \\
\text { associated with ARDS. Mean VT in } \\
\text { patients that developed ARDS, } \\
623.5 \mathrm{ml}\end{array}$ \\
\hline Pasero, 2008 & 3.7 days & $7 \%(n=14)$ & Unknown & Unknown & $2.04(1.03-4.05)$ & 0.042 & $\begin{array}{l}\text { Time of surgery and PEEP also } \\
\text { associated with ARDS }\end{array}$ \\
\hline Hughes, 2010 & Unknown & $28 \%(n=25)$ & $\begin{array}{l}9.0 \mathrm{ml} / \mathrm{kg} \\
\text { PBW (8.3-10.0) }\end{array}$ & $\begin{array}{l}9.3 \mathrm{ml} / \mathrm{kg} \\
\text { PBW (8.3-10.1) }\end{array}$ & $1.0(0.3-3.2)$ & 0.97 & $\begin{array}{l}\text { Intraoperative fluid }>20 \mathrm{ml} / \mathrm{kg} / \mathrm{h} \\
\text { associated with ARDS }\end{array}$ \\
\hline Blum, 2011 & Unknown & $0.2 \%(n=102)$ & $\begin{array}{l}9.2 \mathrm{ml}^{\prime} / \mathrm{kg} \\
\text { PBW }^{\mathrm{c}}\end{array}$ & $9.1 \mathrm{ml} / \mathrm{kg} \mathrm{PBW}^{\mathrm{c}}$ & $0.77(0.62-0.95)$ & 0.02 & $\begin{array}{l}\text { PRBC transfusion strongest } \\
\text { predictor of ARDS }\end{array}$ \\
\hline \multicolumn{8}{|c|}{ Case-control study } \\
\hline Author, year & $\begin{array}{l}\text { Time of } \\
\text { ARDS } \\
\text { onset }\end{array}$ & $\begin{array}{l}\text { Incidence of } \\
\text { ARDS }\end{array}$ & $\begin{array}{l}\text { VT ARDS } \\
\text { Group }\end{array}$ & $\begin{array}{l}\text { VT No-ARDS } \\
\text { Group }\end{array}$ & $O^{d}$ & $p$ & Comments \\
\hline $\begin{array}{l}\text { Fernandez-Perez, } \\
2009\end{array}$ & Unknown & $1.9 \%(n=83)$ & $\begin{array}{l}8.9 \mathrm{ml} / \mathrm{kg} \\
\mathrm{PBW} \pm 1.6\end{array}$ & $\begin{array}{l}8.7 \mathrm{ml} / \mathrm{kg} \text { PBW } \\
\pm 1.7\end{array}$ & $1.03(0.84-1.26)$ & 0.801 & $\begin{array}{l}\text { Time of surgery, transfusion, and } \\
\text { fluid balance associated with } \\
\text { ARDS }\end{array}$ \\
\hline
\end{tabular}

ARDS, acute respiratory distress syndrome; NS, nonsignificant odds ratio (exact value and confidence interval not reported in original manuscript); OR, odds ratio; PEEP, positive end-expiratory pressure; PRBC, packed red blood cell; SAH, subarachnoid hemorrhage; VT, tidal volume. ${ }^{\mathrm{a}}$ Each trial attempted to control for various factors associated with development with ARDS, either with statistical analysis or trial design (for the RCT). ${ }^{b} \mathrm{OR}$ for risk of ARDS as a function of tidal volume.

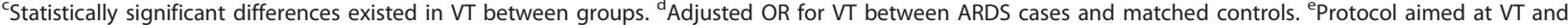
transfusion reduction. VT $10.6 \mathrm{ml} / \mathrm{kg}$ PBW (9.0-12.1) before protocol versus $7.7 \mathrm{ml} / \mathrm{kg}$ PBW (6.7-9.0).

proof of publication bias. Other potential explanations for asymmetry include study-to-study heterogeneity with the intervention fidelity or outcome assessment. Also, improvement in the usual care in the "control" treatment groups as routine management evolves over time may reduce the observed effect size. It is also possible that an asymmetric funnel plot is the result of chance alone [41]. Finally, differences were noted between studies in how a 
Table 3 Clinical outcomes comparing ARDS and nonARDS groups

\begin{tabular}{|c|c|c|c|c|}
\hline Outcome & Author, year & ARDS & $\begin{array}{l}\text { No } \\
\text { ARDS }\end{array}$ & $p$ \\
\hline \multirow[t]{3}{*}{ Mortality } & Kahn, 2006 & $42 \%$ & $19 \%$ & $<0.05$ \\
\hline & $\begin{array}{l}\text { Fernandez-Perez, } \\
2009\end{array}$ & $44 \%$ & $8 \%$ & $<0.001$ \\
\hline & Mascia, 2007 & $28 \%$ & $22 \%$ & NS \\
\hline \multirow[t]{4}{*}{ Hospital mortality } & Gajic, 2004 & $34 \%$ & $24 \%$ & 0.116 \\
\hline & Gajic, 2005 & $62 \%$ & $32 \%$ & \\
\hline & Iscimen, 2008 & $51 \%$ & $18 \%$ & $<0.001$ \\
\hline & $\begin{array}{l}\text { Fernandez-Perez, } \\
2009\end{array}$ & $17 \%$ & $5 \%$ & 0.004 \\
\hline ICU mortality & Iscimen, 2008 & $38 \%$ & $11 \%$ & \\
\hline \multirow[t]{2}{*}{ ICU LOS (days) } & Mascia, 2007 & 25 & 20 & $<0.05$ \\
\hline & Kahn, 2006 & $\begin{array}{l}15 \% \\
\text { increase }\end{array}$ & & $<0.05$ \\
\hline \multirow[t]{2}{*}{ Hospital LOS (days) } & Kahn, 2006 & $\begin{array}{l}7 \% \\
\text { increase }\end{array}$ & & NS \\
\hline & $\begin{array}{l}\text { Fernandez-Perez, } \\
2009\end{array}$ & 17 & 5 & $<0.001$ \\
\hline \multirow[t]{2}{*}{ VF days } & Gajic, 2004 & 17 & 22 & 0.007 \\
\hline & Mascia, 2007 & 11 & 16 & $<0.05$ \\
\hline $\begin{array}{l}\text { Duration of MV } \\
\text { (days) }\end{array}$ & Kahn, 2006 & 14 & 8 & $<0.001$ \\
\hline Renal failure & Kahn, 2006 & $8 \%$ & $2 \%$ & $<0.001$ \\
\hline
\end{tabular}

ARDS, acute respiratory distress syndrome; LOS, length of stay; MV, mechanical ventilation; NS, nonsignificant; VF, ventilator free.

patient was classified as having developed ARDS, even though each study required fulfillment of accepted consensus criteria [2].

The results of this systematic review do reveal some important trends in the data. First, each study that reported ARDS onset showed that it occurs early in mechanically ventilated at-risk patients. This may reflect the difficulty in defining the precise onset of ARDS retrospectively, but also that many mechanically ventilated patients may have early ARDS that has yet to manifest clinically. This suggests that prevention trials should target the most immediate time after initiation of mechanical ventilation (e.g. in the ED, interhospital transport, and/or the first 24 hours of ICU admission). Endotracheal intubation and initiation of mechanical ventilation is a common occurrence in the ED, yet the effect that ED-based mechanical ventilation may have on outcome has not been studied [54]. However, preenrollment data from ARDS clinical trials showed that early tidal volume did not influence mortality, further highlighting the equipoise on this topic [55].

Second, the incidence of ARDS is very low when tidal volume is studied in low risk patients in the operating room $(<2 \%)$. This is in contrast to the ICU, where the progression to ARDS appears to be a significant problem (as high as 44\%). However, in a cohort of higher-risk surgical patients, higher tidal volumes have been associated with other clinical outcomes, including greater nonpulmonary organ failure and an increase in duration of mechanical ventilation and ICU length of stay [56].

Third, although no definitive conclusions between tidal volume and progression to ARDS can be made, based on this systematic review, several findings in this body of evidence suggest a link between higher tidal volumes and progression to ARDS. Although almost all of the data are observational trials, consistent findings across trial design suggest a cause-effect relation [57]. In the only RCT examining this topic to date, tidal volume was predictive of progression to ARDS. Additionally, the majority of the observational data demonstrate an increased ARDS incidence with larger tidal volumes, which also suggests a causal link [57]. A dose-response relation (seen in five studies), with the proportion of ARDS patients increasing with higher tidal volumes, suggests cause-effect, as does the fact that no findings appeared in the opposite direction (no study showed lower tidal volumes to be harmful).

Fourth, the development of ARDS was associated with many other factors across these trials. These include patient-related (e.g. restrictive lung disease [29]), ventilator-related (e.g. airway pressure [47]), and non ventilatorrelated (e.g. fluid balance and transfusion $[35,45,47,49]$ ) factors. This further highlights that the development of ARDS reflects an interaction between patient risk and treatment variables, which was demonstrated before, and suggests that the most effective ARDS-prevention strategy may involve a multimodal approach (e.g. early resuscitation, fluid management and type, lower tidal volume, high transfusion threshold, and so on) $[48,53]$. In addition, future ARDS-prevention trials will need to control for each of these confounding variables while assessing patient populations with similar baseline risk of progressing to ARDS.

Finally, the progression to ARDS is associated with significant increase in morbidity and mortality. In all trials directly comparing ARDS versus no-ARDS groups, mortality (up to fivefold increase), length of stay, and organ failure were all increased with the development of the syndrome. Although the best strategy to prevent the progression to ARDS has not been fully elucidated, it is clear that its prevention should be a high priority in clinical care and further research [58].

Important limitations exist in this systematic review. The only RCT was stopped early, after an unplanned interim analysis, because of safety concerns of ARDS development in the $10-\mathrm{ml} / \mathrm{kg}$ PBW group [44]. Clinical trials stopped early for benefit are increasing in prevalence, often lack information on why the trial was stopped, and routinely show larger than expected treatment effects [59]. The benefit of clinical trials stopped 
early, including the trial in this review, should therefore be viewed with caution. However, with $75 \%$ of the planned enrollment achieved, and a very significant between-group difference for the primary outcome ( $p=$ $0.01)$, confidence is increased that these results are indeed valid.

Second, relatively few studies have examined ARDS prevention and the role of tidal volume in the development of ARDS. Existing studies are limited by their observational trial design, and therefore any attempt to analyze these studies as a group is limited by their individual weaknesses.

Third, a meta-analysis of these data could not be conducted as planned a priori, which differs from another systematic review on this topic [60]. The patients were not qualitatively similar and represent a spectrum of patients from those with very little risk for ARDS (e.g. elective surgery patients) to those with very high risk (e.g. septic shock). When contemplating whether a systematic review should become a meta-analysis, heterogeneity is typically first addressed on a macroscopic level of the individual study's design, population, intervention(s), and outcome measures. If sufficient differences exist between individual studies such that lumping them together is comparing "apples and oranges," then a meta-analysis is not appropriate. Systematic review authors should proceed to meta-analysis only if this first level of heterogeneity is assessed and deemed unlikely, an approach that has been previously advocated [61]. We were therefore able to conduct only a qualitative analysis of the data, as conducting a meta-analysis would have served only to homogenize patients artificially. We recognize that these limitations make drawing recommendations difficult based on this systematic review, but with our inclusion of an additional 10 studies (and >7,000 ICU patients) and strict adherence to reporting guidelines, we believe this current review to be the most complete and methodologically sound assessment of the literature to date.

The focus on early mechanical ventilation and ARDS prevention is likely to increase. Recently the National Heart, Lung and Blood Institute (NHLBI) recommended the development of ARDS prevention trials, as well as observational trials of patients without ARDS undergoing prolonged mechanical ventilation [58]. Given the limited treatment options for ARDS, the period of mechanical ventilation immediately after endotracheal intubation is emerging as a critical time window of clinical care and an opportunity for clinical trials to improve outcome [58]. Our results are important in further highlighting knowledge gaps, which may serve in the future design of ARDS prevention trials, and not only call attention to the limitation of the literature, but also highlight potential solutions for clinical trials going forward. This includes RCTs targeting homogeneous patient groups with higher event rates for ARDS progression and early timing of trial enrollment (e.g. immediately after endotracheal intubation in the ED). Factorial trial design aimed at limiting more than one risk modifier for ARDS progression, such as tidal volume and fluid balance, should be considered to maximize efficiency in this research arena [62]. Future research should aim to minimize bias by incorporating publishing guidelines such as the Consolidated Standards of Reporting Trials (CONSORT) for RCTs and the STROBE for observational trials and should have clinically relevant end points, such as progression to ARDS or development of nonpulmonary organ failure as a surrogate for ventilator-associated lung injury $[40,63,64]$. Finally, to reduce efficiently the preventable heterogeneity and variability in research and clinical care in a sustainable fashion, interventions should be simple, and reproducibility should be enhanced with the aid of implementation science and electronic aids [65-69]. Knowledge of factors influencing a lack of adherence to beneficial therapy in ARDS may aid clinicians in translating research to routine care for prevention of the syndrome as well $[65,70]$. These trials will ultimately influence clinicians and change practice. Therefore, analyzing critically what has and has not been done is of vital importance.

\section{Conclusions}

Currently, no definitive recommendations can be made on the most appropriate tidal volume strategy in mechanically ventilated patients without ARDS. Data suggest an increased incidence of ARDS with higher tidal volumes, but previous studies are limited by their heterogeneity and high variability in baseline ARDS risk among the patients included. Given the increased mortality and morbidity associated with progression to ARDS, a focus on prevention should remain a high priority for future research and clinical practice.

\section{Key messages}

- The majority of data suggest that higher tidal volumes are causal in the development of ARDS.

- An overall lack of quality data prevents a definitive recommendation for the most appropriate tidal volume in patients with ARDS.

- ARDS occurs early in the course of mechanical ventilation, suggesting that ARDS-prevention trials should occur early in the course of mechanical ventilation, such as in the emergency department.

- The development of ARDS is associated with significant increases in mortality and morbidity, suggesting that ARDS-prevention trials are needed. 


\section{Additional material}

Additional file 1: PROTOCOL: Search and identification of studies

This is the search protocol and protocolized strategy, including the inclusion and exclusion criteria that were used capture the studies for this systematic review.

\section{Abbreviations}

AECC: American European Consensus Conference; ALI: acute lung injury; ARDS: acute respiratory distress syndrome; CONSORT: Consolidated Standards of Reporting Trials; ED: emergency department; ICU: intensive care unit; MOOSE: Meta-Analysis of Observational Studies in Epidemiology; NCATS: National Center for Advancing Translational Sciences; NCRR: National Center for Research Resources; NHLBI: National Heart: Lung and Blood Institute; NIH: National Institutes of Health; PBW: predicted body weight; PRISMA: Preferred Reporting Items for Systematic Reviews and Meta-Analysis; $\mathrm{RCT}$ : randomized controlled trial; STROBE: Strengthening the Reporting of Observational Studies in Epidemiology.

\section{Authors' contributions}

BF was responsible for conception and design, acquisition of data, analysis, and interpretation of data. He was also responsible for drafting the article, revising it critically for important intellectual content, as well as final approval of the version to be published. NM contributed to the design, acquisition of data, analysis, and interpretation of data. He was also responsible for drafting the article, revising it critically for important intellectual content, as well as final approval of the version to be published. AD contributed to the design, acquisition of data, analysis, and interpretation of data. She was also responsible for drafting the article, revising it critically for important intellectual content, as well as final approval of the version to be published. CC contributed to the design, acquisition of data, analysis, and interpretation of data. He was also responsible for drafting the article, revising it critically for important intellectual content, as well as final approval of the version to be published.

\section{Competing interests}

The authors declare that they have no competing interests.

\section{Acknowledgements}

The authors thank Susan Fowler, medical librarian at Bernard Becker Medical Library at Washington University in St. Louis. We also thank the contacted authors of several of the manuscripts that were included and excluded in this review. Their time and generosity in responding to our inquiries is much appreciated.

Dr. Fuller acknowledges that this publication was made possible by the National Center for Research Resources (NCRR) and the National Center for Advancing Translational Sciences (NCATS), National Institutes of Health (NIH), through grant number UL1 TR000448. Dr. Carpenter received funding from the Washington University KM1 Comparative Effectiveness Award (1KM1CA156708-01). The content is solely the responsibility of the authors and does not necessarily represent the official views of the $\mathrm{NIH}$.

\section{Author details}

'Department of Anesthesiology, Division of Critical Care, Division of Emergency Medicine, Washington University in St. Louis School of Medicine, 660 South Euclid Avenue, St. Louis, MO, USA. ${ }^{2}$ Department of Emergency Medicine, Department of Anesthesia, Division of Critical Care, Roy J. and Lucille A. Carver College of Medicine, University of lowa, 375 Newton Road, lowa City, IA, USA. ${ }^{3}$ Department of Anesthesiology, Division of Critical Care, Washington University in St. Louis School of Medicine, 660 South Euclid Avenue, St. Louis, MO, USA. ${ }^{4}$ Division of Emergency Medicine, Washington University in St. Louis School of Medicine, 660 South Euclid Avenue, St. Louis, MO, USA.

Received: 24 September 2012 Accepted: 18 January 2013 Published: 18 January 2013

\section{References}

1. Rubenfeld G, Caldwell E, Peabody E, Weaver J, Martin D, Neff M, Stern E, Hudson L: Incidence and outcomes of acute lung injury. N Engl J Med 2005, 353:1685-1693.

2. Bernard GR, Artigas A, Brigham KL, Carlet J, Falke K, Hudson L, Lamy M, Legall JR, Morris A, Spragg R: The American-European Consensus Conference on ARDS: definitions, mechanisms, relevant outcomes, and clinical trial coordination. Am J Respir Crit Care Med 1994, 149:818-824.

3. Rubenfeld GD, Herridge MS: Epidemiology and outcomes of acute lung injury. Chest 2007, 131:554-562.

4. Bersten AD, Edibam C, HUNT T, Moran J: Incidence and mortality of acute lung injury and the acute respiratory distress syndrome in three Australian states. Am J Respir Crit Care Med 2002, 165:443-448.

5. Herridge MS, Tansey CM, Matté A, Tomlinson G, Diaz-Granados N, Cooper A, Guest CB, Mazer CD, Mehta S, Stewart TE: Functional disability 5 years after acute respiratory distress syndrome. N Engl J Med 2011, 364:1293-1304.

6. The Acute Respiratory Distress Syndrome Network: Ventilation with lower tidal volumes as compared with traditional tidal volumes for acute lung injury and the acute respiratory distress syndrome. N Engl J Med 2000, 342:1301-1308

7. Phua J, Stewart TE, Ferguson ND: Acute respiratory distress syndrome 40 years later: time to revisit its definition*. Crit Care Med 2008, 36:2912.

8. The Acute Respiratory Distress Syndrome Network: Ketoconazole for early treatment of acute lung injury and acute respiratory distress syndrome: a randomized controlled trial. JAMA 2000, 283:1995-2002.

9. The ARDS Clinical Trials Network: Randomized, placebo-controlled trial of lisofylline for early treatment of acute lung injury and acute respiratory distress syndrome. Crit Care Med 2002, 30:1-6.

10. Brower RG, Lanken PN, MacIntyre N, Matthay MA, Morris A, Ancukiewicz M, Schoenfeld D, Thompson BT: Higher versus lower positive end-expiratory pressures in patients with the acute respiratory distress syndrome. $N$ Engl J Med 2004, 351:327.

11. Steinberg KP, Hudson LD, Goodman RB, Hough CL, Lanken PN, Hyzy R, Thompson BT, Ancukiewicz M: Efficacy and safety of corticosteroids for persistent acute respiratory distress syndrome. N Engl J Med 2006, 354:1671-1684.

12. Wiedemann $H$, Wheeler $A$, Bernard $G$, Thompson $B$, Hayden $D$, deBoisblanc B, Connors A Jr, Hite R, Harabin A, National Heart and Blood Institute Acute Respiratory Distress Syndrome (ARDS) Clinical Trials Network: Comparison of two fluid-management strategies in acute lung injury. $N$ Engl J Med 2006, 354:2564-2575.

13. Matthay MA, Brower RG, Carson S, Douglas IS, Eisner M, Hite D, Holets S, Kallet RH, Liu KD, Maclntyre N: Randomized, placebo-controlled clinical trial of an aerosolized beta-2 agonist for treatment of acute lung injury. Am J Respir Crit Care Med 2011, 184:561-568.

14. Rice TW, Wheeler AP, Thompson BT, Steingrub J, Rock P: Enteral omega-3 fatty acid, $\gamma$-linolenic acid, and antioxidant supplementation in acute lung injury. JAMA 2011, 306:1574-1581.

15. Esteban A, Alía I, Gordo F, de Pablo R, Suarez J, González G, Blanco J: Prospective randomized trial comparing pressure-controlled ventilation and volume-controlled ventilation in ARDS. Chest 2000, 117:1690-1696.

16. Gattinoni L, Tognoni G, Pesenti A, Taccone P, Mascheroni D, Labarta V, Malacrida R, Di Giulio P, Fumagalli R, Pelosi P: Effect of prone positioning on the survival of patients with acute respiratory failure. $N$ Engl J Med 2001, 345:568-573.

17. Dellinger RP, Zimmerman JL, Taylor RW, Straube RC, Hauser DL, Criner GJ, Davis K, Hyers TM, Papadakos P: Effects of inhaled nitric oxide in patients with acute respiratory distress syndrome: results of a randomized phase II trial. Crit Care Med 1998, 26:15-23.

18. Wheeler A, Bernard G, Thompson B, Schoenfeld D, Wiedemann $H_{\text {, }}$ DeBoisblanc B, Connors A Jr, Hite R, Harabin A: Pulmonary-artery versus central venous catheter to guide treatment of acute lung injury. $N$ Engl J Med 2006, 354:2213-2224.

19. Perkins GD, McAuley DF, Thickett DR, Gao F: The $\beta$-Agonist Lung Injury Trial (BALTI): a randomized placebo-controlled clinical trial. Am J Respir Crit Care Med 2006, 173:281-287.

20. Domenighetti G, Suter PM, Schaller MD, Ritz R, Perret C: Treatment with $\mathrm{N}$ acetylcysteine during acute respiratory distress syndrome: a randomized, double-blind, placebo-controlled clinical study. J Crit Care 1997, 12:177-182. 
21. Abraham E, Baughman R, Fletcher E, Heard S, Lamberti J, Levy H, Nelson L, Rumbak M, Steingrub J, Taylor J: Liposomal prostaglandin E1 (TLC C-53) in acute respiratory distress syndrome: a controlled, randomized, doubleblind, multicenter clinical trial. Crit Care Med 1999, 27:1478-1485.

22. Hubmayr RD: Point: is low tidal volume mechanical ventilation preferred for all patients on ventilation? Yes. Chest 2011, 140:9-11.

23. Gattinoni L: Counterpoint: is low tidal volume mechanical ventilation preferred for all patients on ventilation? No. Chest 2011, 140:11-13.

24. Bendixen $\mathrm{H}$, Hedley-Whyte J, Laver M: Impaired oxygenation in surgical patients during general anesthesia with controlled ventilation: a concept of atelectasis. N Engl J Med 1963, 269:991.

25. Hedley-Whyte J, Laver M, Bendixen H: Effect of changes in tidal ventilation on physiologic shunting. Am J Physiol: Legacy content 1964, 206:891-897

26. Tobin MJ, Chadha T, Jenouri G, Birch S, Gazeroglu H, Sackner M: Breathing patterns. 1. Normal subjects. Chest 1983, 84:202-205.

27. Gattinoni L, Chiumello D, Russo R: Reduced tidal volumes and lung protective ventilatory strategies: where do we go from here? Curr Opin Crit Care 2002, 8:45-50

28. Dreyfuss D, Soler P, Basset G, Saumon G: High inflation pressure pulmonary edema: respective effects of high airway pressure, high tidal volume, and positive end-expiratory pressure. Am J Respir Crit Care Med 1988, 137:1159-1164.

29. Gajic O, Dara SI, Mendez JL, Adesanya AO, Festic E, Caples SM, Rana R, StSauver JL, Lymp JF, Afessa B: Ventilator-associated lung injury in patients without acute lung injury at the onset of mechanical ventilation. Crit Care Med 2004, 32:1817-1824.

30. Gajic O, Frutos-Vivar F, Esteban A, Hubmayr RD, Anzueto A: Ventilator settings as a risk factor for acute respiratory distress syndrome in mechanically ventilated patients. Intensive Care Med 2005, 31:922-926.

31. Mascia L, Zavala E, Bosma K, Pasero D, Decaroli D, Andrews P, Isnardi D, Davi A, Arguis MJ, Berardino M: High tidal volume is associated with the development of acute lung injury after severe brain injury: an international observational study*. Crit Care Med 2007, 35:1815.

32. Koner O, Celebi S, Balci H, Cetin G, Karaoglu K, Cakar N: Effects of protective and conventional mechanical ventilation on pulmonary function and systemic cytokine release after cardiopulmonary bypass. Intensive Care Med 2004, 30:620-626.

33. Wrigge $H$, Zinserling J, Stüber $F$, von Spiegel $T$, Hering $R$, Wetegrove $S$, Hoeft A, Putensen C: Effects of mechanical ventilation on release of cytokines into systemic circulation in patients with normal pulmonary function. Anesthesiology 2000, 93:1413.

34. Iscimen R, Yilmaz M, Cartin-Ceba R, Hubmayr R, Afessa B, Gajic O, Farmer J: Risk factors for the development of acute lung injury in patients with septic shock: an observational cohort study. Crit Care 2008, 12(Suppl 2): P487.

35. Kahn JM, Caldwell EC, Deem S, Newell DW, Heckbert SR, Rubenfeld GD: Acute lung injury in patients with subarachnoid hemorrhage: incidence, risk factors, and outcome. Crit Care Med 2006, 34:196.

36. Liberati A, Altman DG, Tetzlaff J, Mulrow C, Gøtzsche PC, loannidis J, Clarke M, Devereaux P, Kleijnen J, Moher D: The PRISMA statement for reporting systematic reviews and meta-analyses of studies that evaluate health care interventions: explanation and elaboration. J Clin Epidemiol 2009, 62:e1-e34.

37. Stroup DF, Berlin JA, Morton SC, Olkin I, Williamson GD, Rennie D, Moher D, Becker BJ, Sipe TA, Thacker SB: Meta-analysis of observational studies in epidemiology. JAMA 2000, 283:2008-2012.

38. The ARDS Definition Task Force: Acute respiratory distress syndrome: the Berlin definition. JAMA 2012, 307:2526-2533.

39. Higgins J, Altman DG: Assessing risk of bias in included studies. In Cochrane Handbook for Systematic Reviews of Interventions: Cochrane Book Series. Edited by: Green JHaS. Chichester, UK: John Wiley 2008:

40. Von Elm E, Altman DG, Egger M, Pocock SJ, Gøtzsche PC Vandenbroucke JP: The Strengthening the Reporting of Observational Studies in Epidemiology (STROBE) statement: guidelines for reporting observational studies. Bull WHO 2007, 85:867-872.

41. Sterne J, Egger M, Smith G: Investigating and dealing with publication and other biases. Systematic Reviews in Health Care: Meta-analysis in Context. 2 edition. Chatham, UK; 2001

42. Blum J, Stentz M, Park P: Predictors of postoperative acute lung injury in a low incidence surgical population [abstract]. Anesthesiology 2011, 115:A790.
43. Hughes CG, Weavind L, Banerjee A, Mercaldo ND, Schildcrout JS, Pandharipande PP: Intraoperative risk factors for acute respiratory distress syndrome in critically ill patients. Anesth Analg 2010, 111:464-467.

44. Determann RM, Royakkers A, Wolthuis EK, Vlaar AP, Choi G, Paulus F, Hofstra JJ, de Graaff MJ, Korevaar JC, Schultz MJ: Ventilation with lower tidal volumes as compared with conventional tidal volumes for patients without acute lung injury: a preventive randomized controlled trial. Crit Care 2010, 14:R1.

45. Fernández-Pérez ER, Sprung J, Afessa B, Warner DO, Vachon CM, Schroeder DR, Brown DR, Hubmayr RD, Gajic O: Intraoperative ventilator settings and acute lung injury after elective surgery: a nested case control study. Thorax 2009, 64:121.

46. Pasero D, Guerriero F, Rana N, Merigo G, Mastromauro I, Viberti S, Mascia L, Rinaldi M, Ranieri M: High tidal volume as an independent risk factor for acute lung injury after cardiac surgery [abstract]. Intensive Care Med 2008, 34(Suppl 1):398

47. Jia X, Malhotra A, Saeed M, Mark RG, Talmor D: Risk Factors for ARDS in patients receiving mechanical ventilation for $>48 \mathrm{~h}$. Chest 2008, 133:853-861.

48. Yilmaz M, Keegan MT, Iscimen R, Afessa B, Buck CF, Hubmayr RD, Gajic O: Toward the prevention of acute lung injury: protocol-guided limitation of large tidal volume ventilation and inappropriate transfusion*. Crit Care Med 2007, 35:1660.

49. Plurad D, Martin M, Green D, Salim A, Inaba K, Belzberg H, Demetriades D, Rhee $P$ : The decreasing incidence of late posttraumatic acute respiratory distress syndrome: the potential role of lung protective ventilation and conservative transfusion practice. J Trauma 2007, 63:1.

50. STROBE Statement: Strengthening the reporting of observational studies in epidemiology [http://www.strobe-statement.org/index.php?id=strobeendorsement]

51. von Elm E, Altman D: Reporting guidelines: looking back from the future. Chest 2008, 134:682-684.

52. Plint A, Moher D, Morrison A, Schulz K, Altman D, Hill C, Gaboury I: Does the CONSORT checklist improve the quality of reports of randomised controlled trials? A systematic review. Med J Australia 2006, 185:263-267.

53. Gajic O, Dabbagh O, Park P, Adesanya A, Chang SY, Hou P, Anderson III H, Hoth JJ, Mikkelsen ME, Gentile N: Early identification of patients at risk of acute lung injury. Am J Respir Crit Care Med 2011, 183:462-470.

54. Sagarin M, Barton E, Chng Y, Walls R, National Emergency Airway Registry Investigators: Airway management by US and Canadian emergency medicine residents: a multicenter analysis of more than 6,000 endotracheal intubation attempts. Ann Emerg Med 2005, 46:328-336.

55. Checkley W, Brower R, Korpak A, Thompson BT: Effects of a clinical trial on mechanical ventilation practices in patients with acute lung injury. Am J Respir Crit Care Med 2008, 177:1215-1222.

56. Lellouche F, Dionne S, Simard S, Bussières J, Dagenais F: High tidal volumes in mechanically ventilated patients increase organ dysfunction after cardiac surgery. Anesthesiology 2012, 116:1072.

57. Hill $\mathrm{AB}$ : The environment and disease: association or causation? Proc $R$ Soc Med 1965, 58:295.

58. Spragg R, Bernard G, Checkley W, Curtis J, Gajic O, Guyatt G, Hall J, Israel E, Jain M, Needham D, Randolph A, Rubenfield G, Schoenfield D, Thompson B, Ware L, Young D, Harabin A: Beyond mortality: future clinical research in acute lung injury. Am J Respir Crit Care Med 2010, 181:1121-1127.

59. Montori V, Devereaux P, Adhikari N, Burns K, Eggert C, Briel M, Lacchetti C, Leung T, Darling E, Bryant D: Randomized trials stopped early for benefit: a systematic review. JAMA 2005, 294:2203.

60. Neto AC, Manetta JA, Pereira VGM, Esposito DC, Damasceno MCT, Schultz MJ: Association between use of lung protective ventilation with lower tidal volumes and clinical outcomes among patinets without acute respiratory distress syndrome. JAMA 2012, 308:1651-1659.

61. Thompson S: Why sources of heterogeneity in meta-analysis should be investigated. BMJ 1994, 309:1351-1355.

62. Montgomery AA, Peters TJ, Little P: Design, analysis and presentation of factorial randomised controlled trials. BMC Medical Res Methodol 2003, 3:26.

63. Schulz K, Altman D, Moher D, for the CONSORT Group: CONSORT 2010 statement: updated guidelines for reporting parallel group randomized trials. Ann Intern Med 2010, 152:726-732.

64. Equator Network. [http://www.equator-network.org/index.aspx?o = 1032]

65. Needham DM, Colantuoni E, Mendez-Tellez PA, Dinglas VD, Sevransky JE, Himmelfarb CRD, Desai SV, Shanholtz C, Brower RG, Pronovost PJ: Lung 
protective mechanical ventilation and two year survival in patients with acute lung injury: prospective cohort study. BMJ 2012, 344:e2124.

66. Morris AH, Orme J Jr, Truwit JD, Steingrub J, Grissom C, Lee KH, Li GL, Thompson BT, Brower R, Tidswell M: A replicable method for blood glucose control in critically ill patients. Crit Care Med 2008, 36:1787-1795.

67. Morris AH, Orme J Jr, Rocha BH, Holmen J, Clemmer T, Nelson N, Allen J, Jephson A, Sorenson D, Sward K: An electronic protocol for translation of research results to clinical practice: a preliminary report. J Diabetes $\mathrm{SCl}$ Technol (Online) 2008, 2:802.

68. Blagev DP, Hirshberg EL, Sward K, Thompson BT, Brower R, Truwit J, Hite D, Steingrub J, Orme JF, Clemmer TP: The evolution of eProtocols that enable reproducible clinical research and care methods. $J$ Clin Monitor Comput 2012, 26:305-317.

69. Pronovost PJ, Murphy DJ, Needham DM: The science of translating research into practice in intensive care. Am J Respir Crit Care Med 2010, 182:1463-1464.

70. Walkey AJ, Wiener RS: Risk factors for underuse of lung-protective ventilation in acute lung injury. J Crit Care 2012, 27:323, e1-323.e9.

doi:10.1186/cc11936

Cite this article as: Fuller et al: Lower tidal volume at initiation of mechanical ventilation may reduce progression to acute respiratory distress syndrome: a systematic review. Critical Care 2013 17:R11.

\section{Submit your next manuscript to BioMed Central} and take full advantage of:

- Convenient online submission

- Thorough peer review

- No space constraints or color figure charges

- Immediate publication on acceptance

- Inclusion in PubMed, CAS, Scopus and Google Scholar

- Research which is freely available for redistribution

Submit your manuscript at www.biomedcentral.com/submit 